\title{
Gamma function estimates via completely monotonicity arguments
}

\section{CRISTINEL MORTICI}

\section{ABSTRACT.}

The aim of this paper is to improve some recent results of Sandor and Debnath [On certain inequalities involving the constant e and their applications J. Math. Anal. Appl. 249 (2000) 569-582] and Batir [Sharp inequalities for factorial $n$ Proyecciones 27 (2008) 97-102] about the problem of approximation of gamma function. In proving the results in this paper, the proofs are not completely analytic but essentially based on formal computations obtained by means of software packages.

DEPARTMENT OF MATHEMATICS

VALAHIA UNIVERSITY

UNIRII 18, 130082 TÂRGOVIŞTE, ROMANIA

E-mail address: cmorticievalahia.ro

Received: 31.10.2010; In revised form: 30.06.2011; Accepted: 30.11.2011

2010 Mathematics Subject Classification. 33B15, 26D15, 40A25.

Key words and phrases. Gamma function, approximations, asymptotic series, inequalities. 